\title{
The Effectiveness of Behavioral-Developmental Approach Intervention to Enhancing Verbal and Performance Cognitive Ability on Children with Autism Spectrum Disorders
}

\author{
Ernie Chairuni Siregara, Sunaryo Kartadinata ${ }^{b}, Z^{a}$ aenal Aliminc, Yoga Budhi Santoso ${ }^{\mathrm{d}}$

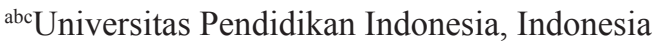 \\ ${ }^{\mathrm{d} U n i v e r s i t a s}$ Islam Nusantara, Indonesia \\ Email: erniecsiregar@student.upi.edu
}

\begin{abstract}
The purpose of this research is to discover the result of an intervention using a behavioraldevelopmental approach to verbal and performance cognitive ability of children with autism spectrum disorders. This study employed a within-group experiment using a single-subject $\mathrm{A} / \mathrm{B}$ design. The intervention was given to two children under the age of four by combining learning activities whose curriculum was very well structured with play activities that could stimulate him to interact with others in a more natural setting. The intervention program was given by an educator and parents for 40 hours/ a week in twelve months. The results of the study revealed that the behavioral-developmental approach is effective in improving both verbal and performance cognitive ability. this research is expected to become an alternative intervention to improve cognitive ability in children with autism spectrum disorders.
\end{abstract}

Keywords: performance cognitive ability, verbal ability, autism spectrum disorder, behavioraldevelopment approach

\section{INTRODUCTION}

Currently, there two mainstream approaches in the treatment of children with autism spectrum disorders, there are behavioral and developmental approaches (Prizant \& Wetherby, 1998; Greenspan \& Wieder, 2006; Siegel, 2010; Ross, 2012). Both approaches have two different viewpoints on philosophy, methods, and targets of treatment.

According to pervasive disorders in children with autism spectrum disorders (ASD), there's no single approach can deal with all the problems of children. To improve child development significantly and comprehensively, multiple approaches are required to deal with children in synergies because one approach can complement disadvantages of the other approach (Fey, 1986; Siegel, 2010, Nee, 2013).

The wide variety of problems that exist in children, differences in learning speed, potential differences and learning problems in each child is a challenge in providing treatment to children with ASD (Siegel, 2010). Using a strategy of intervention by combining a behavioral-development approach is an intervention that combines philosophy, methods, and techniques that exist in behavioral approaches and developmental approaches.

Behavioral-development approach is done by combining the advantages of handling with existing methods on behavioral and developmental approaches. Techniques used in this strategy are techniques used in applied behavioral methods but the selection of materials appropriate to the stage of child development. This strategy involving educators, parents, and peers as well as integrating a structural-artificial and natural handling environment. Behavioral-developmental approach's target not only develop cognitive abilities and shape functional learning behaviors such as behavioral approaches but also emphasize building interactions between children and parents, family and social (Leaf et al., 2008; Matson, 2009; Farrel, 2012; Greenspan \& Wieder, 2006; Ross, 2012).

\section{METHOD}

The experimental research design used was the type Within Group/Individual Design in the form of Single-Subject Experiment with A/B Design. Design of this study was chosen because the study subjects had a very wide diversity of problems and found it difficult to find research subjects with similar profiles, requiring individual analysis and minimizing the threat of internal validity (Cooper et al., 2007).

The participants of this study were not taken randomly and use Quasi-Experiment (Creswell, 2002). Research participants are two children (2) who had been diagnosed with ASD, had no physical problems and was less than four (4) years old in March 2016 (based on the consideration that children under four have the transfer of learning ability better than children over the age of four (Lovaas, 1987). 
Table 1. Cognitive Ability

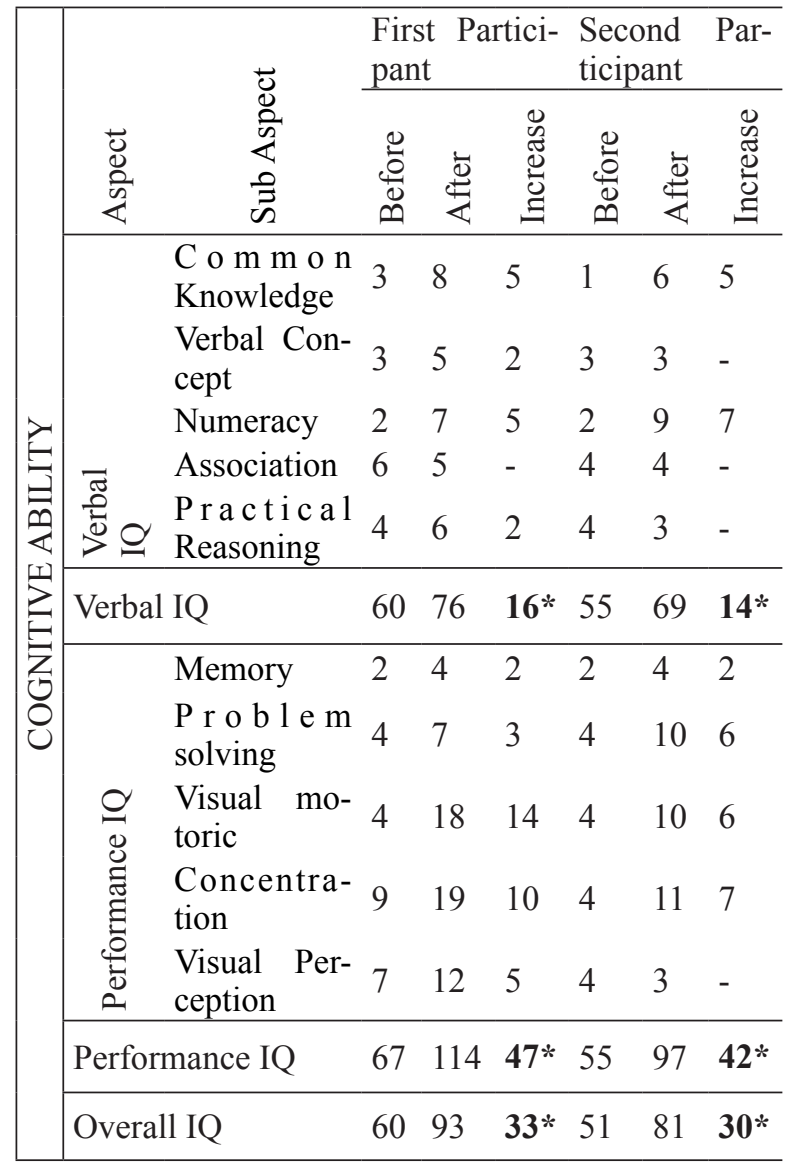

test before the intervention (Anastasi \& Urbina, 2007).

Educator, who has over-three-month experienced in giving intervention and parents, who received 40 hours of training, conduct intervention twelve (12) months in autism service center in Bandung City-West Java, Indonesia and child's parent house.

The intervention activities occurred in a classroom at the autism service center and at home for 30 hours/ a week or 6 hours/a day in 4 sessions (each session was 90 minutes). The educator did his part at the autism service center, and the parent did theirs at home. To measure the cognitive ability, WPPSI (Wechsler Preschool and Primary Scale of Intelligence) test was used. The test was administered by administered by a professional psychologist. The WPPSI test was divided into two types of intelligence tests; one is to measure verbal comprehension (Verbal IQ), and the other to measure the spatial relational ability and non-verbal reasoning (Performance IQ) (Gregory, 2004). The results of the two aspect subtests, verbal IQ, and performance IQ, were interpreted in the forms of full-scale IQ scores.

The researcher would consider the intervention was adequately successful if after the intervention the child got a 10 point increase from baseline full-scale IQ score of the result of WPPSI in table 1.

\section{FINDINGS AND DISCUSSION}

\section{Findings}

\section{Participant 1}

There is an increase of 16 points on verbal intelligence's first participant after receiving the intervention. That means first participant's verbal comprehension skills, including the ability to learn verbal materials and apply verbal skills to solve various problems-increased significantly $(>10$ points). However, point increase does not change verbal intelligence criteria, so first participant's verbal intelligence norm remains at very low criteria compared to children of the same age.

Due to posttest, the first participant gets 47 points on performance intelligence. That means the ability and understanding of space, including non-verbal reasoning, image/space imagery, and the ability to process picture information significantly increased $(>$ 10 points). Point increase also increases the criteria of first participant's performance intelligence, from very low to above average than children of the same age.

In overall intelligence, there's a 33 point increase after being handled. That means the ability of the first participant in facing the environment effectively increases significantly ( $>10$ points). In addition, the first participant 's overall intelligence criteria rise, from very low criteria become average criteria than the average child with the same age.

\section{Participant 2}

There's an increase of 14 points on verbal intelligence after receiving treatment. That means first participant's verbal comprehension skills, including the ability to learn verbal materials and apply verbal skills to solve various problems increased significantly $>10$ points). However, point increase does not change verbal intelligence criteria, so second participant's verbal intelligence remains at very low criteria compared to children of the same age.

Due to posttest, second participants get 42 points on performance intelligence. That means the ability and understanding of space, including non-verbal reasoning, image/space imagery, and the ability to process picture information significantly increased (> 10 points). There are increases criteria of the second participant's performance intelligence, from very low to average than children of the same age.

In overall intelligence, there's a 30 point increase after being handled. That means the ability of the second participant in facing the environment effectively increases significantly ( $>10$ points). In addition to the increase in numbers, second participant 's overall intelligence criteria are on the rise, from very 
low become low average criteria than the average child with the same age.

\section{Discussion}

Based on results, intervention with behavioraldevelopmental approach can improve cognitive abilities significantly. Combination of a structural learning-artificial and a natural play setting can develop the child's cognitive abilities. Involving parents and educators can increase children's motivation to learn from the environment. Once the child has mastered the language skills, the child is included in the school activities and interacts with peers to maintain the behavior of the children who have been formed.

The child addressed in this study demonstrated similar cognitive abilities to the child's age and demonstrated his ability to manage himself well enough, showed interest in the environment, was able to establish attachment relationships with others, was able to convey his thoughts and feelings in simple form, was able to express ideas, and two-way communication.

\section{CONCLUSION}

The behavioral-developmental approach is effective in improving both verbal and performance cognitive ability. The child demonstrated similar cognitive abilities to the child's age and demonstrated his ability to manage himself well enough, showed interest in the environment, was able to establish attachment relationships with others, was able to convey his thoughts and feelings in simple form, was able to express ideas and two-way communication.

This research is expected to become an alternative intervention to improve cognitive ability in children with autism spectrum disorders.

\section{REFERENCES}

Anastasi, A., \& Urbina, S. (2007). Tes Psikologi, Edisi Ketujuh (Terjemahan). Jakarta: PT Indeks.

Cooper, J. O. H., Heward, T. E., William, L., Cooper, J. O., Heron, T. E., \& Heward, W. L. (2007). Applied behavior analysis. New Jersey: Pearson
Creswell, J. W. (2002). Educational research: Planning, conducting, and evaluating quantitative (pp. 146166). Upper Saddle River, NJ: Prentice Hall.

Farrel, M. (2012). The special education handbook: an AZ guide. Routledge.

Fey, M. E. (1986). Language intervention with young children. San Diego, CA: College-Hill Press.

Greenspan, S. T., \& Wieder, S. (2006). The Child with Special Needs (Anak Berkebutuhan Khusus). Terjemahan). Jakarta Penerbit Yayasan Ayo Main.

Gregory, R. J. (2004). Psychological testing: History, principles, and applications. Allyn \& Bacon.

Leaf, R. B., Taubman, M. T., \& McEachin, J. (2008). Sense and nonsense in the behavioral treatment of autism: It has to be said. New York, NY: DRL Books.

Lovaas, O. I. (1987). Behavioral treatment and normal educational and intellectual functioning in young autistic children. Journal of consulting and clinical psychology, 55(1), 3.

Matson, J. L. (2009). Applied behavior analysis for children with autism spectrum disorders. New York: Springer.

Nee, J. E. (2013). Behavior \& Developmental Treatment Models for Autism Spectrum Disorders: Factors Guiding Clinician Preference and Perceptions.

Prizant, B. M., \& Wetherby,A. M. (1998). Understanding the Continuum of Discrete-Trial Traditional Behavioral to Social-Pragmatic Developmental Approaches in Communication Enhancement for Young Children With Autism/Pdd. Seminars in Speech and Language, 19(4), 329-353.

Ross, R. K. (2012). ABA and DIR/Floortime: Compatible or Incompatible?. West Coast Conference on Autism. Cambridge Center for Behavioral Studies: Buellton-CA.

Siegel, B. (2010). ABA is Too Much: an Overview of Treatment Recommendations for ASD. 9th Annual UCSF Developmental Disabilities Conference. San Francisco 